\title{
Polyimide Films from Vapor Deposition: Toward High Strength, NIF Capsules
}

\author{
C. C. Roberts \\ S. A. Letts \\ M. Saculla \\ E. J. Hsieh \\ R. C. Cook
}

This paper was prepared for submittal to the

Target Fabrication Meeting '98

Jackson Hole, WY

April 19-23, 1998

October 16, 1998

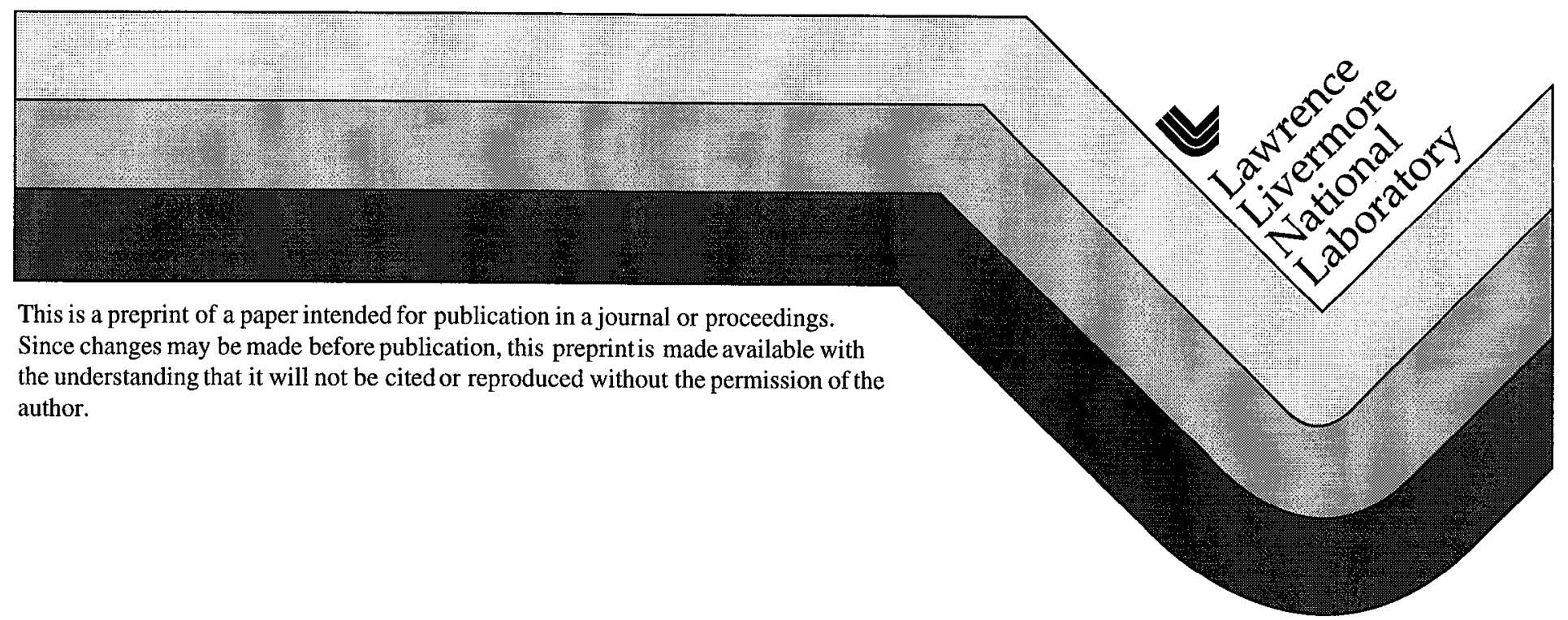


DISCLAIMER

This document was prepared as an account of work sponsored by an agency of the United States Government. Neither the United States Government nor the University of California nor any of their employees, makes any warranty, express or implied, or assumes any legal liability or responsibility for the accuracy, completeness, or usefulness of any information, apparatus, product, or process disclosed, or represents that its use would not infringe privately owned rights. Reference herein to any specific commercial product, process, or service by trade name, trademark, manufacturer, or otherwise, does not necessarily constitute or imply its endorsement, recommendation, or favoring by the United States Government or the University of California. The views and opinions of authors expressed herein do not necessarily state or reflect those of the United States Government or the University of California, and shall not be used for advertising or product endorsement purposes. 


\title{
POLYIMIDE FILMS FROM VAPOR DEPOSITION: TOWARD HIGH STRENGTH, NIF CAPSULES
}

\author{
C. Chad Roberts, Stephan A. Letts, \\ Mike Saculla, Edmund J. Hsieh and Robert C. Cook \\ Lawrence Livermore National Laboratory \\ Livermore, CA 94551
}

(925)423-6490

\begin{abstract}
The focus of recent efforts at LLNL has been to demonstrate that vapor deposition processing is a suitable technique to form polyimide films with sufficient strength for current national ignition facility target specifications. Production of polyimide films with controlled stoichiometry was acccomplished by: 1) depositing a novel co-functional monomer and 2) matching the vapor pressure of each monomer in PMDA/ODA co-depositions. The sublimation and deposition rate for the monomers was determined over a range of temperatures. Polyimide films with thicknesses up to $30 \mu \mathrm{m}$ were fabricated. Composition, structure and strength were assessed using FTIR, SEM and biaxial burst testing. The best films had a tensile strength of approximately $100 \mathrm{MPa}$. A qualitative relationship between the stoichiometry and tensile strength of the film was demonstrated. Thin films $(-3.5 \mu \mathrm{m})$ were typically smooth with an $\mathrm{rms}$ of $1.5 \mathrm{~nm}$.
\end{abstract}




\section{Introduction}

One current National Ignition Facility (NIF) target design calls for a 2-mm-diam. capsule with about a $150-\mu \mathrm{m}$-thick carbon-based ablator (wall). ${ }^{1}$ For ignition experiments commencing in $\sim 2005$, these capsules will be fielded at cryogenic temperatures with an $80 \mu \mathrm{m}$ thick solid DT layer on the inner wall. At room temperature this amount of DT would produce a gas pressure of 360 atm, which corresponds to an internal tensile (total circumferential and radial) stress of $120 \mathrm{MPa}^{2}$ The current plasma polymer ablator materials ${ }^{3}$ do not have enough strength to hold this fill at room temperature. Thus, all handling of these capsules, from the time of the DT fill until the ignition experiment, must be conducted at cryogenic temperatures. This process is both extremely expensive and limiting with respect to fielding options. As originally proposed by Sanchez and Letts $^{2}$, commercial polyimide films have tensile strengths in the range of $230-420 \mathrm{MPa}$, and hence, a polyimide ablator should have sufficient strength to hold the required DT fill. Compared to Be, another ablator option, polyimide shells offer the added advantages of: 1) being diffusion fillable, 2) allowing optical access to frozen fuel layer and 3) permitting the possibility of solid DT layer enhancement by $\operatorname{IR}^{4}$ or joule heating. ${ }^{5}$ Also, recent calculations show that for DT ice layers with surface roughness of 1-1.5 $\mu \mathrm{m}$ rms (typical for $\beta$-layering), ${ }^{6}$ polyimide capsules will perform almost as well as Be capsules and much better than plasma polymer capsules with equivalent surface finishes. ${ }^{7}$ Thus, the focus of this research is to demonstrate capsule fabrication techniques using high strength polyimide materials.

Before proceeding, let us briefly review some relevant aspects of polyimide chemistry. Polyimides (PI) have found numerous applications in aerospace and electronic components, and their success is due to excellent mechanical properties, low dielectric constant, superb thermaloxidative stability and two-stage processing techniques. A number of reviews have been published..$^{8-11}$ Polyimides are typically synthesized from the reaction of diamines and dianhydrides. As illustrated in Figure 1, pyromellitic dianhydride (PMDA) and 4,4'-oxydianiline (ODA) react in solution to form the poly(amic acid) precursor which is thermally converted to a 


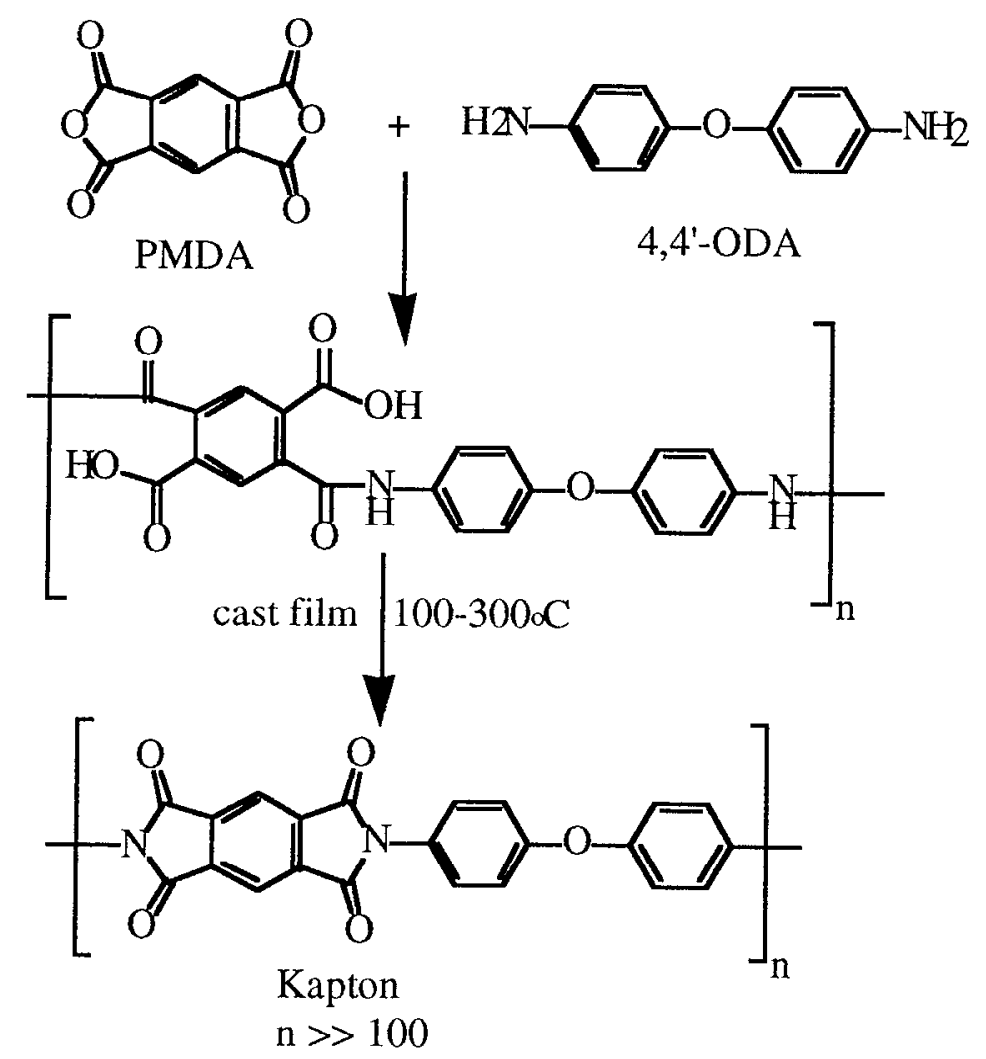

Figure 1. Traditional synthesis of polyimides

poly $\left(4,4^{\prime}\right.$-oxydiphenylene pyromellitimide) film, also known as Kapton ${ }^{\mathrm{TM}}$ (a registered trademark of Du Pont Chemical Co.). Rigid/semicrystalline polyimide films are typically formed from poly(amic acid) solutions by dispensing a coating and heating to $200-300^{\circ} \mathrm{C}$. Controlling the molar ratio, $r$, of diamine and dianhydride is crucial to obtaining high molecular weight, $M W$, polymer. ${ }^{12}$

The tensile properties are of primary concern for a NIF target. The tensile strength of a polymer film depends on: 1) packing density of the polymer (chemical structure), 2) chain length and 3) microstructure and imperfections in the materials (microvoids and crystalline regions). The tensile strength, $\delta$, of a polymer varies with molecular weight (MW) according to the equation:

$\delta=A-B /(M W)$ 
where $A$ and $B$ are constants dependent upon the nature of the polymer. ${ }^{13.14}$ Figure 2 depicts the effect of molecular weight on the tensile strength of Kapton ${ }^{\mathrm{TM}} \cdot{ }^{15,16}$ The general features of this structure-property curve may also be applied to other rigid polyimides. Therefore, the data have been normalized with respect to the maximum predicted tensile strength for infinite molecular weight polymer (constant A) to allow comparison with other high strength polyimide formulations. As illustrated, a minimum molecular weight is required for a polymer to have any mechanical integrity or strength. For Kapton ${ }^{T M}$ this value corresponds to approximately $10 \mathrm{Kg} / \mathrm{mol}$. Note, the strength of polyimides reaches $80 \%$ of the theoretical strength at a molecular weight of around 75 $\mathrm{Kg} / \mathrm{mol}$, and the tensile strength drops off rapidly as molecular weight decreases below 50 $\mathrm{Kg} / \mathrm{mol}$. Commercial Kapton ${ }^{\mathrm{TM}}$ has a tensile strength of $230 \mathrm{MPa}$, but the tensile strength for Upilex $^{\top M}$ (Figure 3, a registered trademark of Ube Industries Ltd.) is $400 \mathrm{MPa}^{17,18}$ A NIF capsule allowing with a $200 \%$ safety margin would have a tensile strength of about $60 \%$ of the tensile strength for solution-casted Upilex ${ }^{\mathrm{TM}}$. Using the Kapton ${ }^{\mathrm{TM}}$ molecular weight vs. strength curve, one can estimate that a polyimide based on the Upilex ${ }^{\mathrm{TM}}$ formulation should have a molecular weight of at least $35 \mathrm{Kg} / \mathrm{mol}$, and therefore the variation in molar ratio must not exceeding $1 \%$.

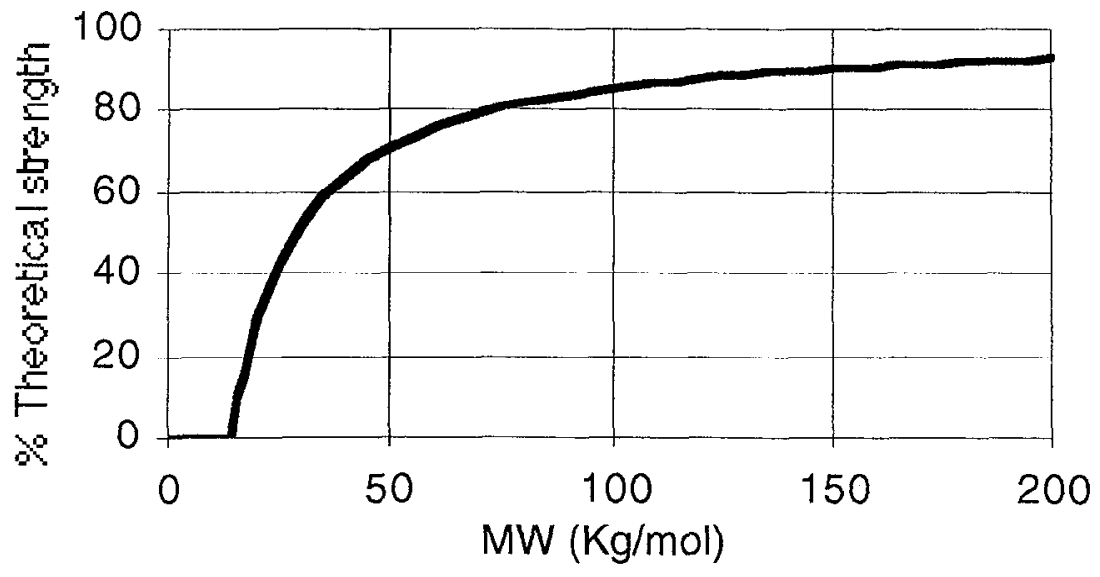

Figure 2. Percent theoretical strength of Kapton ${ }^{\mathrm{TM}}$ as a function of molecular weight - 


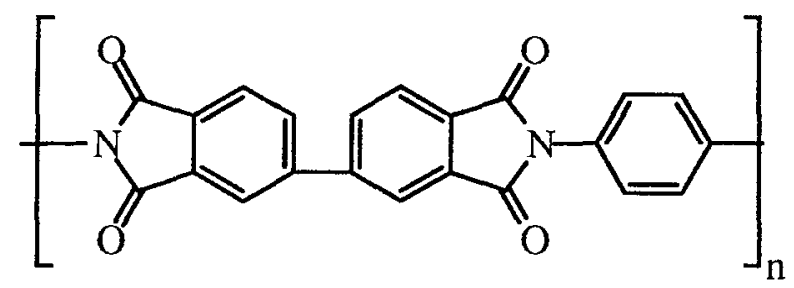

Figure 3. Chemical structure of Upilex ${ }^{\mathrm{TM}}$

Polyimide films have been produced using vapor deposition processing (VDP). In 1986, Salem et al. ${ }^{19}$ at IBM vapor deposited ODA and PMDA. Depositions were carried out in a standard bell jar system equipped with two monomer evaporators, rate monitors for each evaporator and a mixing oven. After curing at $175^{\circ} \mathrm{C}$ and $300^{\circ} \mathrm{C}$, Kapton-like films were obtained. Over the last 10 years, the formation of polyimide films via vapor deposition has been reported by a number of researchers. ${ }^{20-24}$ Most of this work has been directed at microelectronics applications with typical coating ranging from submicron to a few microns thick. All of this work was performed using a coating chamber in which the substrate is suspended at the top and the vapor sources are at the bottom. Unfortunately, the production of polyimide shells requires the reverse configuration.

During the course of our work, Alfonso et al. ${ }^{25}$ at University of Rochester's Laboratory for Laser Energetics (LLE) reported some useful results using a VDP approach with PMDA and ODA. First, and perhaps most importantly, they have demonstrated that a two monomer system could be successfully coated onto plastic shell mandrels using a bounce pan technique. Further they have demonstrated that poly( $\alpha$-methylstyrene), PoMS, capsules overcoated with PMDA/ODA could be thermally imidized at $300^{\circ} \mathrm{C}$ to form polyimide shells with $10 \mu \mathrm{m}$ thick walls; the underlying P $\alpha$ MS mandrel simultaneously decomposed to monomer vapor ${ }^{26}$ which diffused 
through the PMDA/ODA coating. In contrast to LLNL, LLE is interested in making targets for the Omega laser direct drive experiments, which require very thin shells, approximately $1 \mathrm{~mm}$ in diameter. For example, typical UR/LLE polyimide shells were 700-950 $\mu \mathrm{m}$ in diameter and $2-10$ $\mu \mathrm{m}$ thick. $^{25}$

In what follows we will review our recent work at LLNL. In the next section, we will discuss our efforts control the stoichiometry by vapor depositing a single monomer which contains both the amine and anhydride moieties. Following this we describe our progress with the dual monomer system which has focused on the PMDA/ODA formulation. Since a large database of information exists concerning Kapton ${ }^{\mathrm{TM}}$, efforts have been focused on PMDA/ODA co-deposition to develop the VDP technique before switching to the high strength Upilex-STM formulation. The final section reviews our current status.

\section{Single (AB) monomer experiments}

$\mathrm{AB}$ monomers have both functional groups required to form a particular polymer. In the case of polyimides, $\mathrm{AB}$ monomers contain both an amine and anhydride moiety. Thus, good stoichiometry is assured, and theoretically, formation of high molecular weight polymer is possible. In 1988 , Numata et al. ${ }^{27}$ disclosed polyimide film formation via vapor deposition of $A B$ monomers. Following Numata's example, we investigated three AB monomers, 3APA, 4APA and 4ANA, whose structures are shown in Figure 4.<smiles>Nc1cccc2c1C(=O)OC2=O</smiles>

3APA

3-aminophthalic anhydride<smiles>Nc1ccc2c(c1)C(=O)OC2=O</smiles>

4APA

4-aminophthalic anhydride<smiles>Nc1ccc2cc3c(cc2c1)C(=O)OC3=O</smiles>

4ANA

4-aminonaphthalic anhydride

Figure 4. Examples of $\mathrm{AB}$ monomers 


\section{A. Experimental Procedure}

These VDP experiments were performed using a modified sputtering vacuum system with 14 by 9 -in. cylindrical chamber equipped with a mechanical pump. A single monomer evaporator (a hollow cylinder, 2.25 by 3 -in. high) was suspended approximately $5 \mathrm{~cm}$ above the substrate holder. Glass slides ( 2 by 3 -in.) and $\mathrm{KBr}$ discs were typically used as substrates. In the vacuum system at $\sim 50 \mathrm{mTorr}, 3 \mathrm{APA}$ was heated in the evaporator to $150^{\circ} \mathrm{C}$ and vapor deposited on a $\mathrm{KBr}$ disc forming a uniform, coating. The powdery coating was heated in air at $250^{\circ} \mathrm{C}$ for $1 / 2$ hour and converted to a yellow film, which was determined to be polyimide.

\section{B. Results and Discussion}

FTIR was used to determine the structure of 3 APA after heating and peak assignments were made according with Takekoshi ${ }^{28}$ and Silverstein $e t a l .^{29}$ The initial coating was identical to the 3APA starting material and exhibited FTIR absorptions at 3375 \& 3471 (amine N-H), 3228 (C$\mathrm{H}$ ), 1822 \& 1770 (anhydride $\mathrm{C}=\mathrm{O}$ ), and $1249 \mathrm{~cm}^{-1}$ (amine $\mathrm{C}-\mathrm{N}$ ). Heating of the as-deposited, unreacted monomer coating resulted in obvious changes in the FTIR spectrum. The expected shift in $\mathrm{C}=\mathrm{O}$ absorption peak from anhydride around $1820-1770 \mathrm{~cm}^{-1}$ to the imide at $1780-1720 \mathrm{~cm}^{-1}$ is observed along with the appearance of $\mathrm{C}-\mathrm{N}$ imide peaks around 1350 and $1100 \mathrm{~cm}^{-1}$ and the respective loss in amine absorptions around $3500-3380 \mathrm{~cm}^{-1}$. Significant amounts of poly(amic acid) are present after heating to $200^{\circ} \mathrm{C}$ as indicated by the $\mathrm{C}=\mathrm{O}$ absorption at $1610 \mathrm{~cm}^{-1}$. Upon continucd heating at $250^{\circ} \mathrm{C}$, the intensity of the amic acid $\mathrm{C}=\mathrm{O}\left(1610 \mathrm{~cm}^{-1}\right)$ and aminc $\mathrm{C}-\mathrm{N}(1260$ $\mathrm{cm}^{-1}$ ) absorptions decreases. Hence, according to the FTIR data, the film from the thermal processing of 3APA was polyimide with significant amounts of residual poly(amic acid).

The SEM photos of the 3APA coating before and after thermal processing are shown in Figure 5 . The curing process resulted in over $90 \%$ mass loss. The polyimide film formed was very smooth $(0.6 \mathrm{~nm}$ rms by $\mathrm{AFM})$, in contrast to the as-deposited film. Depositions of $4 \Lambda \mathrm{PA}$ and $4 \Lambda \mathrm{NA}$ were attempted under similar conditions. However, these experiments either resulted in no coating or a scattered, powdery coating which did not form a film upon thermal treatment. 

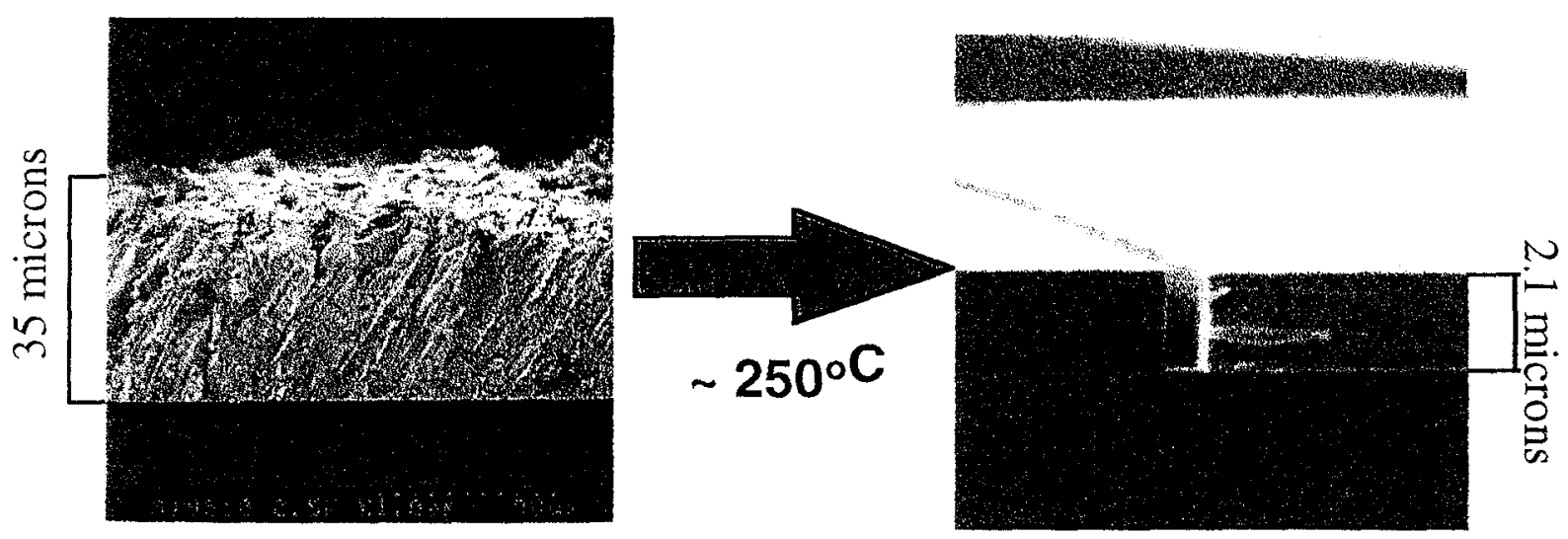

AFM, 0.6 nm RMS

Figure 5. Film from 3APA deposition

To understand these results, these $\mathrm{AB}$ monomers were analyzed using differential scanning calorimetry (DSC), thermal gravimetric analysis (TGA) and hot stage microscopy. The DSC and TGA thermograms for 3APA are depicted in Figure 6. The DSC, performed using a hermetically sealed pan, shows three endotherms. The first endotherm is clearly the melting point and corresponds to values reported in the literature. ${ }^{30}$ The other two transitions are most likely due to the polymerization and imidization, respectively. Using hot-stage microscopy, melt flow of 3APA was observed around $190-200^{\circ} \mathrm{C}$, but this melt did not recrystallize upon cooling.

As expected from the deposition experiments, TGA revealed an initial weight loss for $3 \mathrm{APA}$ around $100^{\circ} \mathrm{C}$, and the residual weight at $300^{\circ} \mathrm{C}$ was slightly less than 10 weight percent. Obviously, the vaporization of 3APA competes strongly with polymerization. In the TGA of $4 \mathrm{APA}$, only $89 \%$ residual mass is observed at $400^{\circ} \mathrm{C}$, and since $11 \%$ weight loss accounts for the expected water loss, conversion of 4APA to the respective polyimide is suggested. The DSC of 4APA depicts a broad exotherm at $194-205^{\circ} \mathrm{C}$. Although no transition is visually observed using hot-stage microscopy, the FTIR of the baked 4APA powder confirms the presence of the imide moiety by the shift of the carbonyl peaks from 1830 and $1760 \mathrm{~cm}^{-1}$ to 1780 and $1720 \mathrm{~cm}^{-1}$. Hence, although a true melt transition is not observed for 4APA upon heating, it apparently polymerizes 
around $200^{\circ} \mathrm{C}$ in the solid state. Similar thermal properties were observed for the other $\mathrm{AB}$ monomer that was examined, 4ANA.

In summary, thermal treatment of the vapor deposited 3APA coating resulted in resublimation of most of the monomer and formation of a relatively thin polyimide film. 4APA and 4ANA suffered from the opposite problem. The vapor pressure remains low as the monomer temperature approaches the melting point, and the reactivity is such that the monomer reacts in the solid state before a true melt is formed. An ideal AB monomer must be inactive initially allowing for facial evaporation. This monomer would then need to be converted to an active form during or after deposition to form non-volatile polymer. Work toward the synthesis and vapor deposition of such a monomer is ongoing.

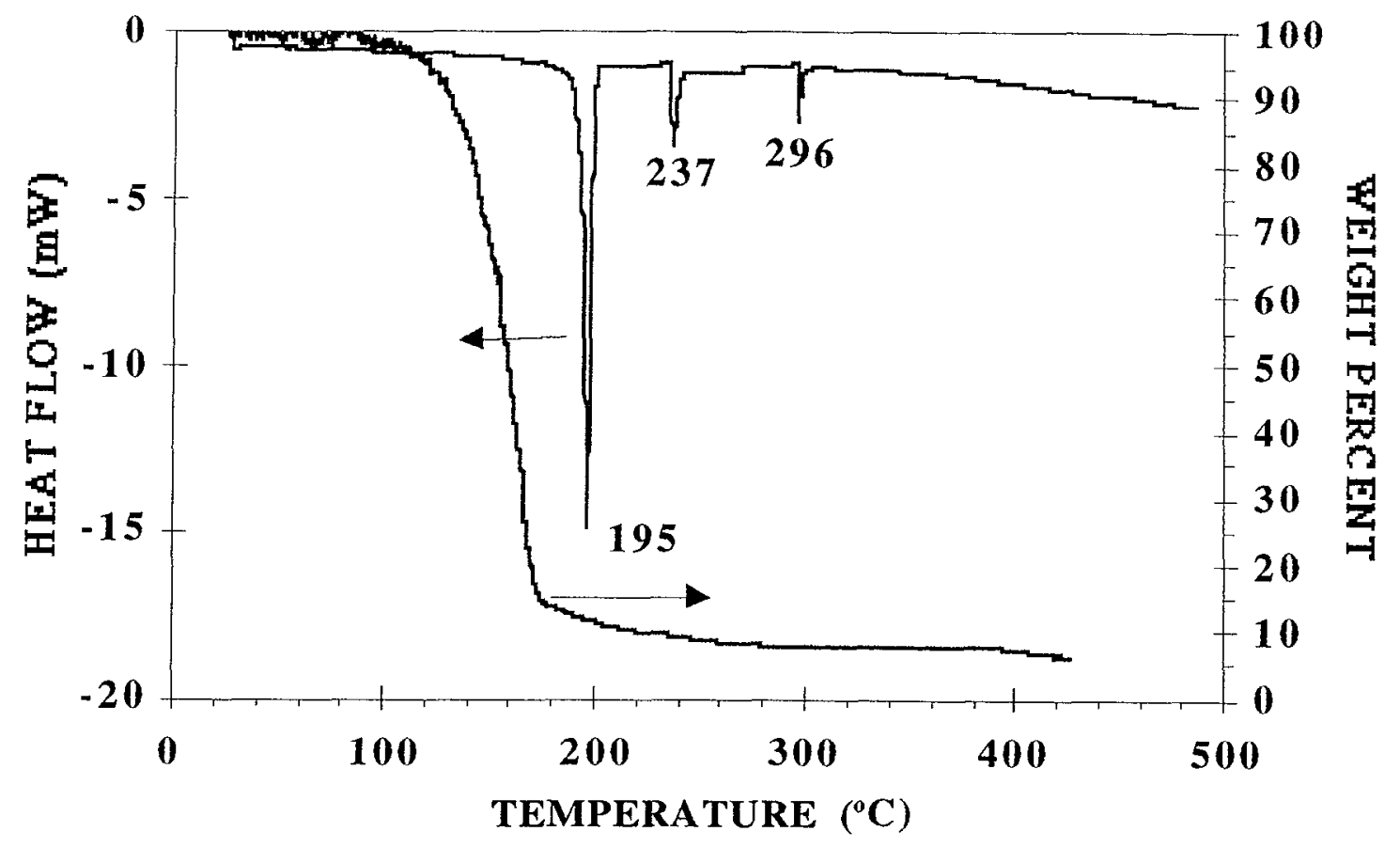

Figure 6. Thermal Analysis of 3APA 


\section{Dual monomer experiments}

Most of our efforts have focused on optimizing the dual monomer coating system by controlling the vapor flux of PMDA and ODA. Initially, FTIR was used to provide a measure of the relative ratio of PMDA and ODA deposited. However, this technique lacks the require precision due to overlapping absorption bands. Instead, we calibrated the vapor deposition process in terms of evaporation and deposition rate of PMDA and ODA as a function of temperature. In addition, we utilized the fact that tensile strength is a sensitive indicator of polyimide molecular weight which in turn is a strong function of the PMDA/ODA ratio. ${ }^{11,12}$

\section{A. Deposition Equipment and Materials}

Our current polyimide coating system is depicted in Figure 7. A 6-in, 6-arm stainless steel cross was used as the deposition chamber. The deposition chamber was pumped down using a diffusion pump backed with a mechanical pump and was capable of reaching pressures in the $10^{-7}$ Torr range with a full $\mathrm{N}_{2}(1)$ trap in line. Two identical evaporators were used to sublime PMDA and ODA. An internal channel directed the vapors toward to the substrate. Each evaporator had an internal, usable volume of $2 \mathrm{ml}$ allowing for a maximum loading of $1.5 \mathrm{~g}$ of PMDA and ODA powder. The evaporator was attached to the heater post, and a cartridge heater (Omcga Enginecring) was used to heat the heater post. The temperature was monitored using a type $\mathrm{K}$ thermocouple and controlled via a proportional-integrated-derivative controller (Cole-Parmer) within $\pm 0.2^{\circ} \mathrm{C}$. The substrate holder was set at a distance of $6 \mathrm{~cm}$ from the evaporators and was capable of being rotated during the vacuum deposition experiment via a rotary mechanical feedthru (MDC Vacuum Products). Polymer grade PMDA (pyromellitic dianhydride) and ODA (4,4'oxydianiline) were obtained from Chriskev Company. The PMDA was recrystallized from acetic acid with 30 wt. \% acetic anhydride, dried in a vacuum oven $\left(\sim 1 \mathrm{Torr}, 80^{\circ} \mathrm{C}\right.$ for overnight and $120^{\circ} \mathrm{C}$ for $3 \mathrm{hr}$ ). The bulk was separated into individual, sealed aliquots of less than $1 \mathrm{~g}$. This insured the PMDA powder was totally anhydrous. The ODA was used as received. 

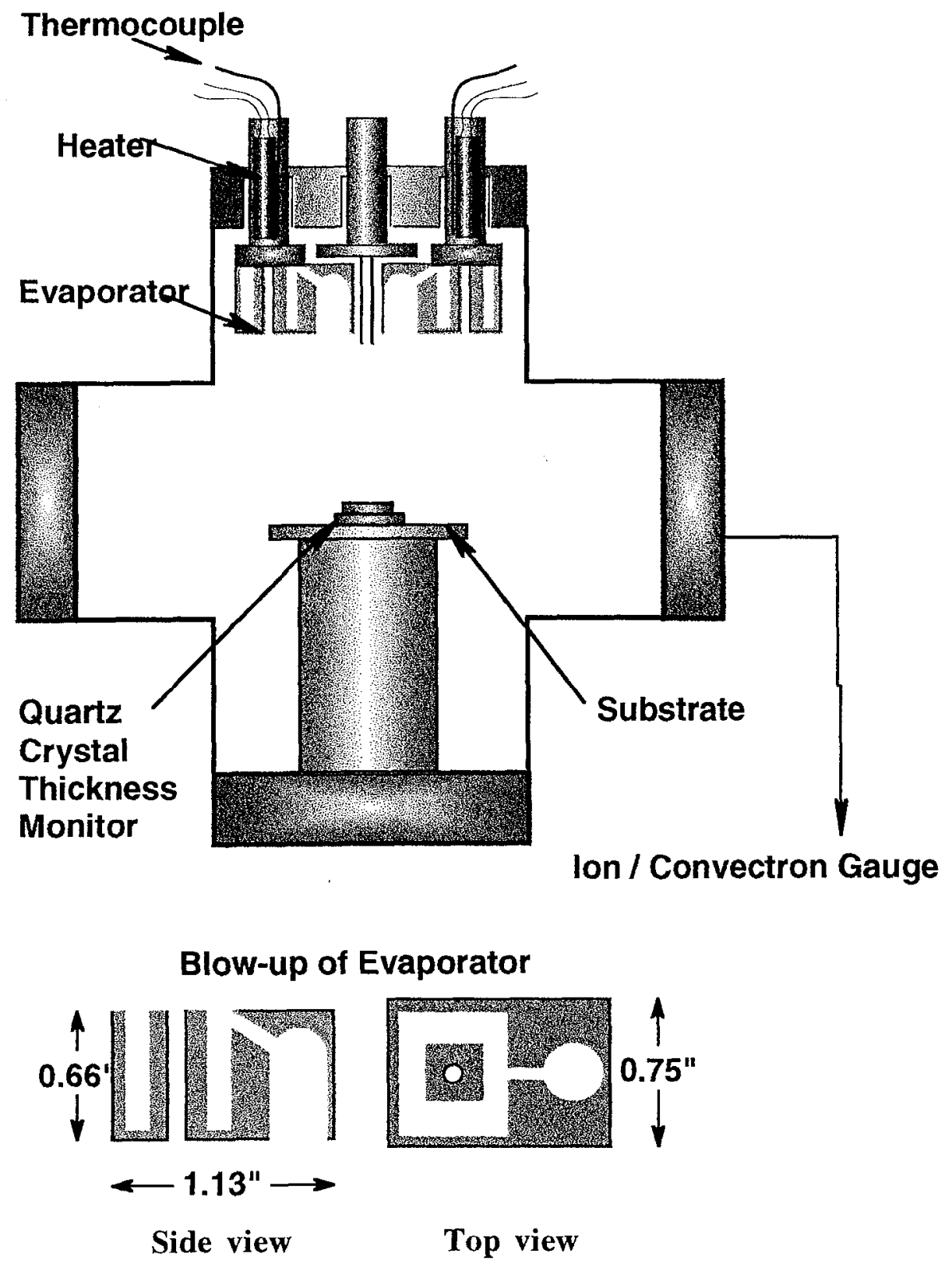

Figure 7. Schematic of polyimide dual monomer, vapor deposition chamber 


\section{Calibration of Deposition Process}

The vapor deposition process was characterized using both the mass loss from monomer evaporators and deposition rate on the substrate. The average-molar-mass-loss rate provides a measure of the vapor flow rate out of the evaporator. The monomer evaporators were loaded, weighed, placed in the vacuum chamber and heated for $3 \mathrm{hr}$. This process was repeated for both PMDA and ODA over a range of temperatures. Figure 8 depicts the measured molar mass-lossrate for each monomer as a function of $1 / \mathrm{T}$. A quartz crystal (QC) deposition rate monitor was utilized to determine the deposition rate as a function of evaporator temperature for each monomer independently. The vibrational frequency of the QC changes proportionally to the mass of the material deposited. The deposition rate monitor assumes a density of $1.00 \mathrm{~g} / \mathrm{ml}$ and converts the mass deposition rate to a thickness deposition rate. ${ }^{31,32}$ For the purposes of our experiments, this thickness deposition rate was converted back to a mass deposition rate using the surface area of the QC. Then the molar deposition rate was obtained from the mass deposition rate. The results are depicted in Figure 9. Note, at a given temperature, the deposition rate is proportional to the molarmass-loss rate. For example, the ratio of the PMDA deposition and the molar-mass-loss rates varies from $1.2 \%$ at $130^{\circ} \mathrm{C}$ to $0.95 \%$ at $160^{\circ} \mathrm{C}$. 
Temperature $\left({ }^{\circ} \mathrm{C}\right)$

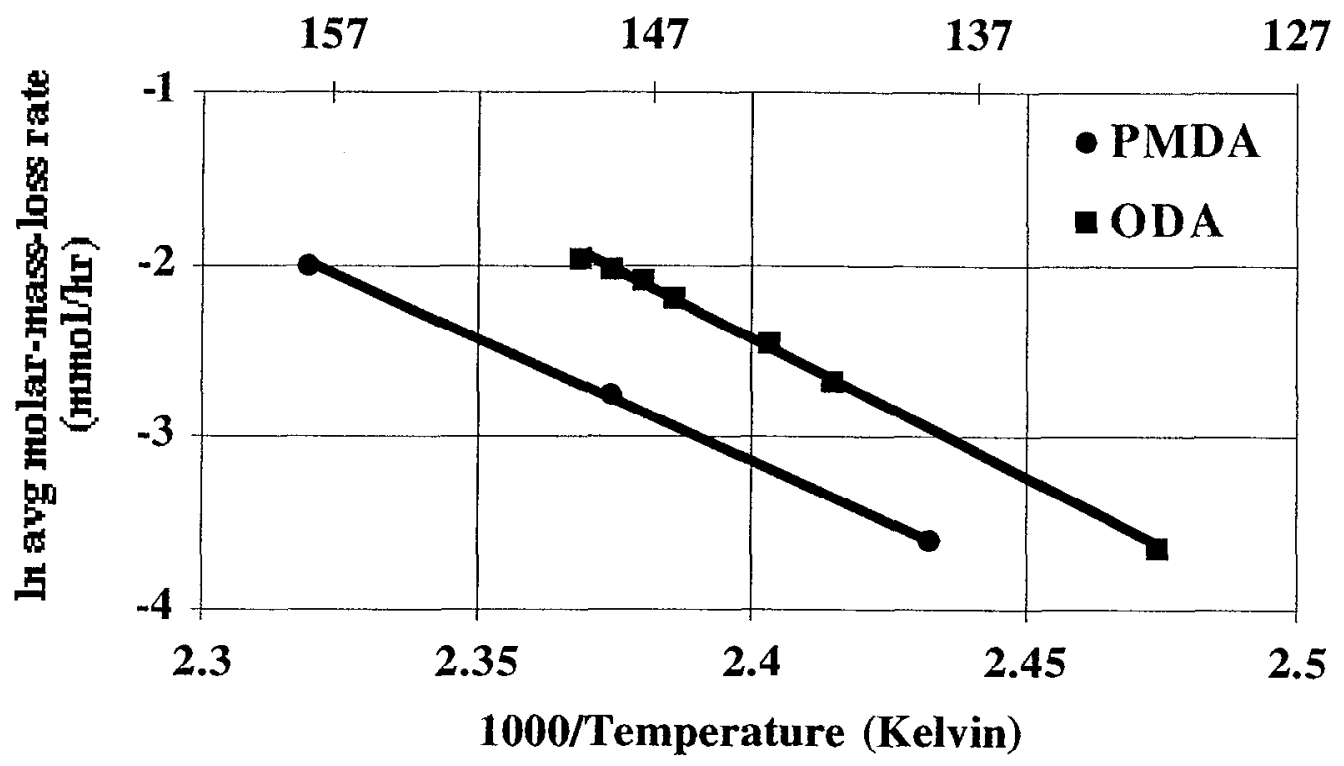

Figure 8. Comparison of ODA and PMDA molar mass loss as a function of Temperature

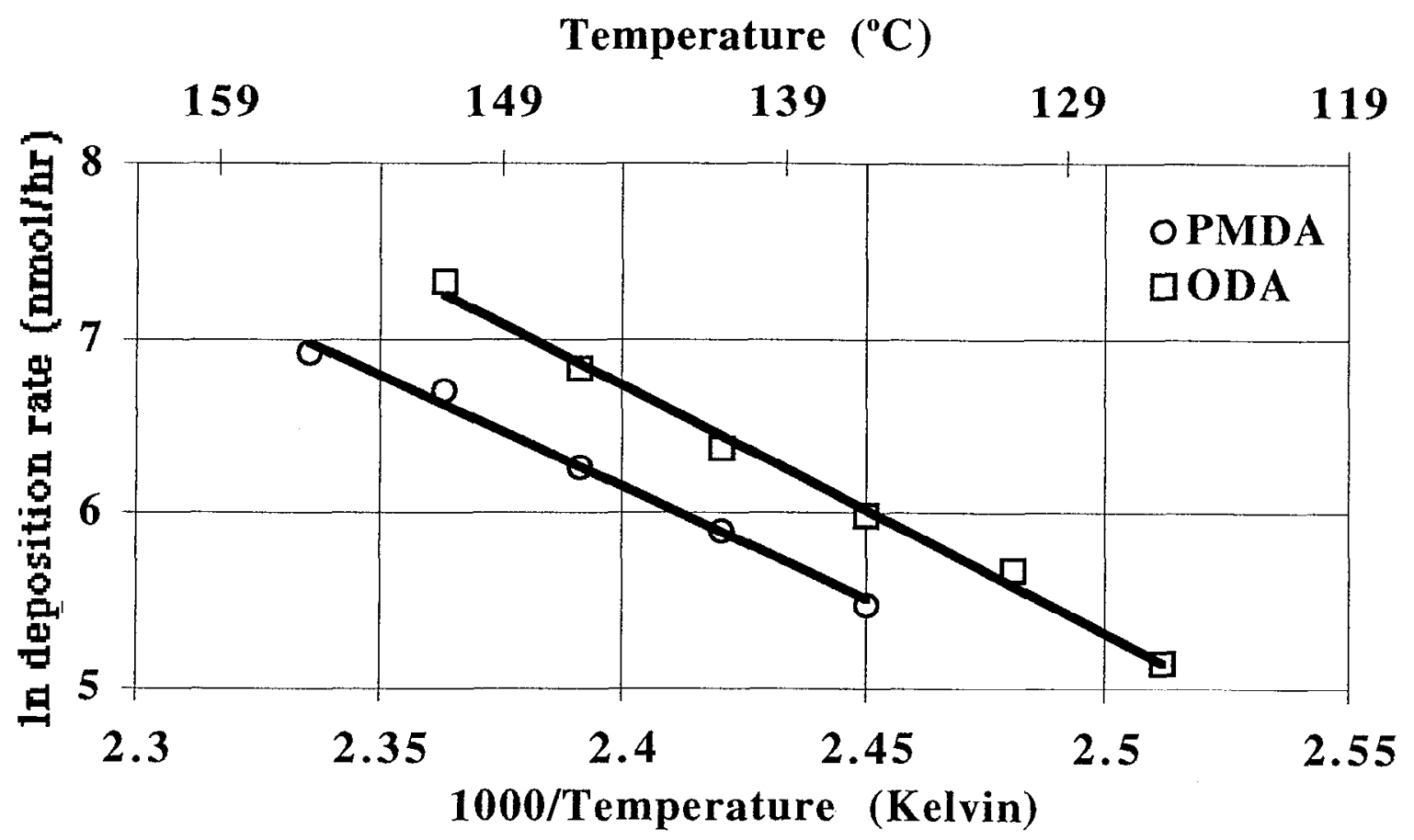

Figure 9. Comparison of deposition rate vs. 1/Temperature for PMDA and ODA

For an ideal monomer evaporator, the conductance of the orifice will be small compared to the overall evaporation rate, and the monomer vapor pressure in the evaporator will be constant 
after an induction period. Assuming that the vapor is in molecular flow through the orifice, the effusion or mass flow rate, $G$, of monomer exiting our evaporator is given by:

$$
G=K A P \sqrt{\frac{2 M}{\pi R T}}
$$

where $A, P, M, R, T$ are cross-sectional area of the orifice, pressure, molar mass, gas constant and temperature, respectively ${ }^{33,34} K$ is the transmission probability or Clausing's factor which accounts for the orifice's geometry and is given by:

$$
K=\frac{1}{1+3 l / 8 r}
$$

where $l$ and $r$ are the length and radius of the orifice, respectively. ${ }^{33}$ For our evaporator, $K$ equals 0.184. Using the above cxpressions, the molar-mass-loss data (Figure 8) was utilized to calculate the monomer vapor pressurc as a function of temperature for PMDA and ODA. This data, depicted in Figure 10 as solid symbols, follows an Arrhenius relationship as described by the ClausisClaperon equation ${ }^{35}$ $\ln P=A-\frac{\Delta H_{s}}{R T}$

The heat of sublimation, $\Delta H_{s}$, can be obtained from the slope of this plot. The calculated $\Delta H_{s}$ for PMDA and ODA are: 118 and $134 \mathrm{~kJ} / \mathrm{mol}$, respectively. Using deposition rate data from a quartz crystal rate monitor, Pethe et $a l^{36}$ calculated the $\Delta H_{s}$ for PMDA and ODA to be 100 and 170 $\mathrm{kJ} / \mathrm{mol}$, respectively. Sublimation enthalpies of 120 and $130 \mathrm{~kJ} / \mathrm{mol}$ for PMDA and ODA, respectively, were reported by Hutchings et $a l^{37}$ using similar rate monitor data.

As discussed by Pethe ${ }^{36}$, Hutchings ${ }^{37}$ and others ${ }^{38}$, the rate of change in the quartz crystal's resonant frequency due to the depositing mass is related to the monomer vapor pressure in the evaporator by the following equation:

$$
P=\frac{d v}{d t} \frac{\pi^{l .5} R_{e s}^{2}}{A_{e} v_{o}^{2}} \sqrt{\frac{\sigma \rho T k_{b}}{2 M}}
$$


where $\frac{d v}{d t}, v_{o}, \mathrm{R}_{\mathrm{es}}, \mathrm{A}_{\mathrm{e}}, \rho, \sigma, \mathrm{k}_{\mathrm{b}}$, and $\mathrm{M}$ are rate of change in the resonant frequency of the quartz crystal, fundamental resonant frequency of quartz, the evaporator to substrate distance, cross-sectional area of the evaporator's orifice, density of quartz crystal, shear modulus of quartz, Boltzmann's constant, and monomer molar mass, respectively. The mass deposition rate, $\frac{d m}{d t}$, is related to $\frac{d v}{d t}$ by the Sauerbrey equation. ${ }^{39}$

$$
\frac{d v}{d t}=\frac{-2 v_{o}^{2}}{A_{e} \sqrt{\sigma \rho}} \frac{d m}{d t}
$$

Hence, vapor pressure inside the monomer evaporator as a function of molar deposition rate is given by the equation:

$$
P=\frac{d m o l}{d t} \frac{4 \pi^{1.5} R_{e s}^{2}}{A_{e} A_{s}} \sqrt{2 T R M}
$$

where $\frac{d m o l}{d t}, \mathrm{~A}_{\mathrm{s}}, \mathrm{R}$ are the observed molar deposition rate, cross-sectional area of the exposed part of the quartz crystal or substrate, and the gas constant. Thus, molar deposition rate data, depicted in Figure 9, was used to calculate the monomer vapor pressure in the evaporator. This data was also plotted in the form of $\ln P=A-\frac{\Delta H_{s}}{R T}$ and is depicted in Figure 10 (open symbols) for comparison with the vapor pressure calculations based on mass loss data. The calculated $\Delta H_{s}$ based on the deposition rate data for PMDA and ODA are: 109 and $120 \mathrm{~kJ} / \mathrm{mol}$, respectively. Thus, our $\Delta \mathrm{H}_{\mathrm{s}}$ data is self-consistent within experimental error $(\sim 10 \%)$ and comparable with similar measurements using vapor deposition equipment.

Since the molar-mass-loss data correlates with the deposition rate data, monitoring of the. mass loss after a PMDA/ODA co-deposition experiment provides quite reasonable method 
assessing the as-deposited stoichiometry. One may also utilize the deposition rate data (Figure 7) to set evaporator temperatures and attempt to match the deposition rate of PMDA and ODA. However, the deposition rate data is for PMDA and ODA deposited independently, and the deposition rates can not be monitored during an actual deposition experiment. In addition, since PMDA is electron poor and ODA is electron rich, ${ }^{40}$ PMDA and ODA will mutually attract each other and react during a co-deposition experiment. Therefore, it is certain that the co-deposition of PMDA and ODA results in significantly different deposition rates. For this reason, we have chosen to control stoichiometry by setting the temperature of the monomer evaporators and hence the vapor flux raining down on the substrate.

Temperature $\left({ }^{\circ} \mathrm{C}\right)$

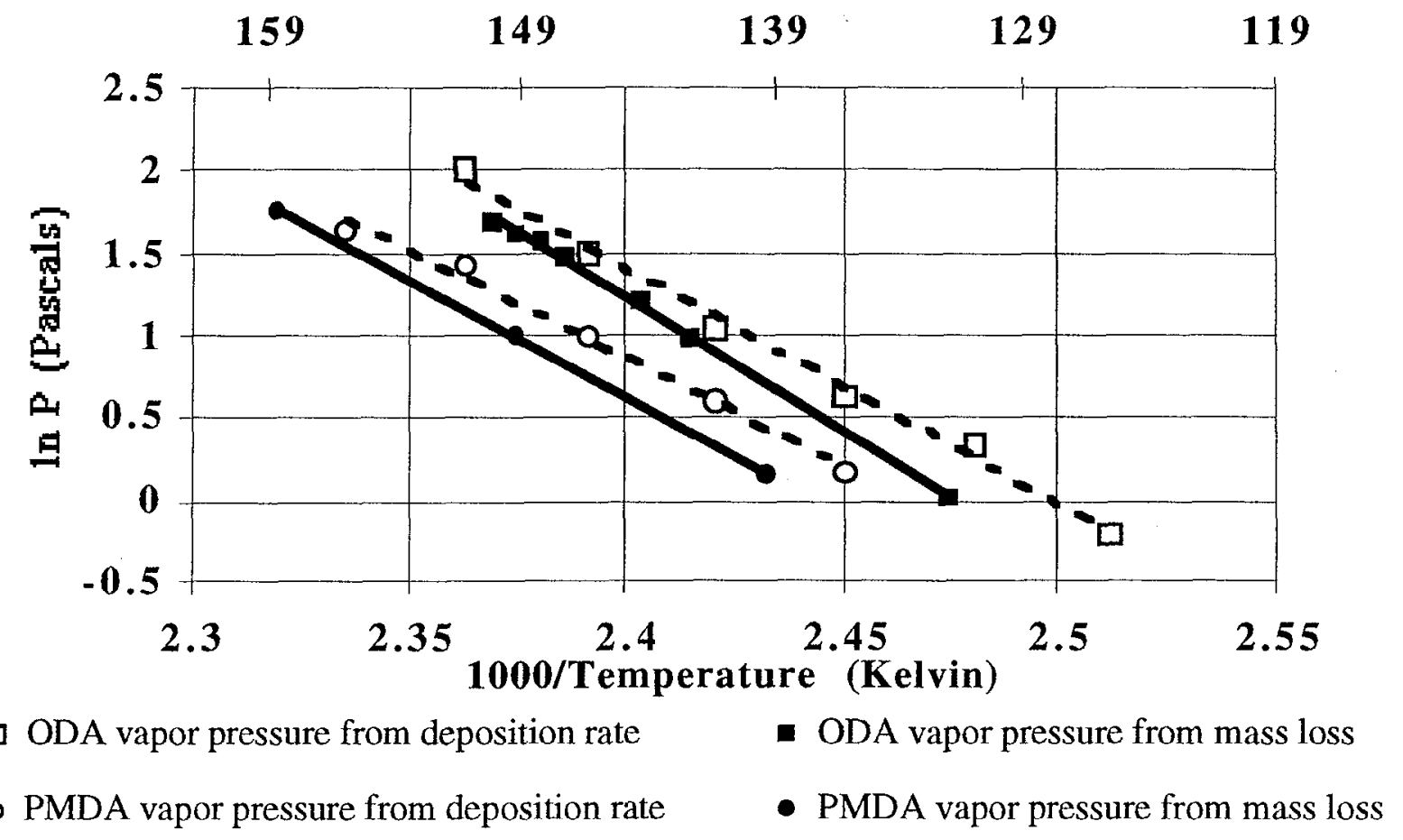

Figure 10. Vapor pressure curves for PMDA and ODA

\section{PMDA/ODA Co-depositions}

In order to optimize the strength of cured polyimide films, number of coatings were deposited at various monomer molar-mass-loss ratios onto $\mathrm{KBr}$ pre-coated glass substrates. 
General experimental conditions were as follows: PMDA evaporator at $158^{\circ} \mathrm{C}$, ODA evaporator at $145-150^{\circ} \mathrm{C}$, base pressure of $2 \times 10^{-6} \mathrm{Torr}$, and coating time of 3 hours. The substrate was rotated at 20-25 rpm to homogenize monomer fluxes during the coating process. Coating rates of $3-3.5$ $\mu \mathrm{m} / \mathrm{hr}$ were typically observed. The PMDA/ODA coated glass slides were thermally treated in a $\mathrm{N}_{2}$ purged muffle furnace as follows: ramp to $150^{\circ} \mathrm{C}$ over $1 / 2$ hour, hold at $150^{\circ} \mathrm{C}$ for $1 / 2$ hour, ramp to $225^{\circ} \mathrm{C}$ over $1 / 2$ hour, hold at $225^{\circ} \mathrm{C}$ for $1 / 2$ hour, ramp to $300^{\circ} \mathrm{C}$ over 1 hour, and hold at $300^{\circ} \mathrm{C}$ for 2 hour. Cured films were lifted off by soaking the coating in water. The films were then rinsed with ethanol and dried in a fume hood. Typical cured polyimide films were $9-10 \mu \mathrm{m}$ thick and exhibited FTIR bands at $1780(\mathrm{CO}), 1710(\mathrm{CO}), 1370(\mathrm{CN})$ and $720(\mathrm{CO}) \mathrm{cm}^{-1}$ confirming the presence of the imide moiety. ${ }^{28}$ The conversion of poly(amic acid) to polyimide was monitored by the bands near 2900-3200 (COOH and NH2), $1710(\mathrm{CO})$, and $1660(\mathrm{CO}) \mathrm{cm}^{-1}$ which diminished as the thermal cycle progressed.

Table 1 compares the tensile strength for a selection of VDP films and the observed mass loss of each monomer from the respective source chamber. Film biaxial tensile strength was measurcd using a film burst apparatus, depicted in Figure 11. The tensile stress at burst was calculated using the measurcd differential pressure and the radial strain. For cxample, film D was pressurized to $365 \mathrm{KPa}$ and rose $0.89 \mathrm{~mm}(\Delta \mathrm{h})$ just before bursting. The film was $9.0 \mathrm{~mm}$ thick, and the calculated radius of curvature was $4.65 \mathrm{~mm}$. Thus, the $\sigma_{\text {burst }}$ for film D was $94 \mathrm{MPa}$. Tensile stress at burst varied from $\sim 50-110 \mathrm{MPa}$. In the case of the stronger films, mechanical testing yielded the lower limit of the film strength due to the presence of micron size defects, which caused the film to prematurely leak rather than burst. As expected the strength of the films varied, in a qualitative sense, with the flux ratio of the monomers. The strongest films were vapor deposited closest to an equal molar ratio of PMDA and ODA. Film E was deposited under conditions, which should be slightly closer to equal molar stoichiometry, compared to conditions for film D. However, film D clearly had a higher tensile strength. Excess diamine is known to - 
cause side reactions and oxidation leading to general deterioration of film properties. ${ }^{28}$ Clearly, the tensile strength of the polyimide film is highly dependent upon the monomer ratio as calculated from the mass-loss data.
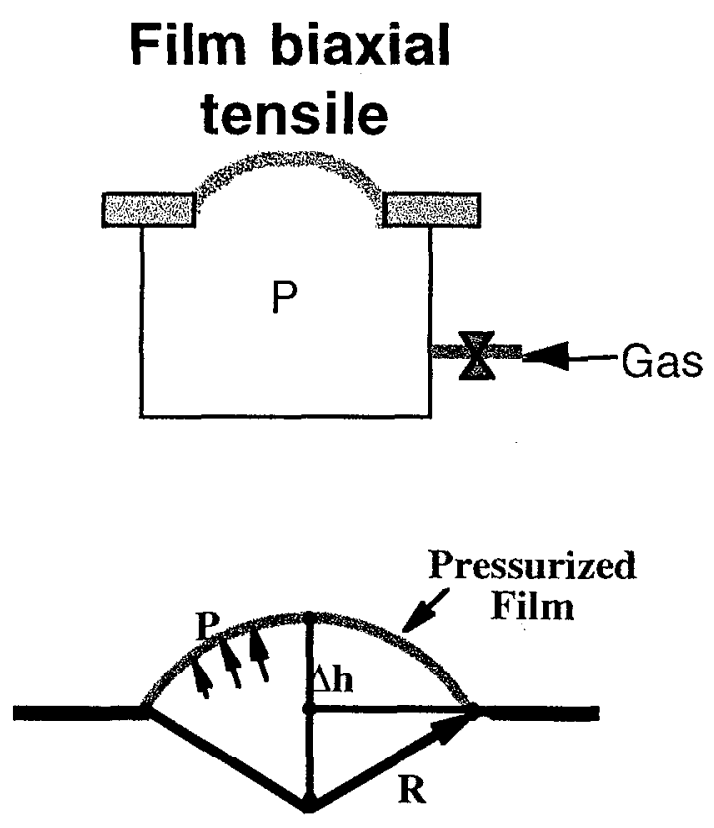

$$
\sigma=\frac{\mathbf{P R}}{2 \mathbf{t}}
$$

$$
\begin{aligned}
& \sigma=\text { tensile stress in film } \\
& R=\text { radius of curvature } \\
& P=\text { pressure on film } \\
& t=\text { thickness of film }
\end{aligned}
$$

Figure 11. Biaxial film testing apparatus and illustration of tensile strength calculation 


\begin{tabular}{|c|c|c|c|c|}
\hline Film ID & $\begin{array}{l}\text { PMDA mass } \\
\text { Ioss (mg) }\end{array}$ & $\begin{array}{l}\text { ODA mass } \\
\text { loss (mg) }\end{array}$ & $\begin{array}{l}\text { PMDA/ODA } \\
\text { Molar Ratio* }\end{array}$ & Tensile strength \\
\hline $\bar{A}$ & 85.6 & 59.2 & 1.33 & Too brittle to test \\
\hline$\overline{\mathrm{B}}$ & 63.8 & 47.7 & 1.23 & High defect density \\
\hline $\bar{C}$ & 88.8 & 70.2 & 1.16 & $<50 \mathrm{MPa}$ \\
\hline$\overline{\mathrm{D}}$ & 63.2 & 53.0 & 1.10 & $\begin{array}{l}>94 \mathrm{MPa} \text { leaks due to defects; } \\
\text { uniform strength }\end{array}$ \\
\hline$\overline{\mathrm{E}}$ & 62.3 & 69.5 & 0.97 & $\begin{array}{c}>84 \mathrm{MPa} \text { in central region; not } \\
\text { uniform \& dark }\end{array}$ \\
\hline $\bar{F}$ & 62.4 & 69.5 & 0.83 & Too brittle to test \\
\hline
\end{tabular}

Table 1. Summary of tensile testing results of VDP polyimide films of various compositions

* Molar ratio of the monomer sublimed from each monomer source

\section{Conclusions}

We have examined vapor deposition of both single and dual monomers (PMDA/ODA).

The single monomer deposition experiments had mixed results. Although the coating was smooth and homogenous, over $90 \%$ of the initial monomer coating sublimed during thermal curing to form polyimide. For PMDA/ODA co-depositions, stoichiometry control was examined by measuring the monomer sublimation and deposition rates as a function of temperature. The vapor pressure curves generated using this data were comparable. The molar-mass-loss ratio was found to be an adequate method of judging the stoichiometry of the as-deposited PMDAVDA coating. A number of coatings were deposited with different stoichiometries, and the thermal conversion of the as deposited PMDA/ODA coating to polyimide was monitored using FTIR. The biaxial strength of these polyimide films was used to optimize the VDP parameters. The films with stoichiometry close to 1:1 exhibited the highest tensile strengths. Clearly current films are close to the minimum strength specification for a NIF quality capsule (120 MPa). Commercial Kapton ${ }^{\mathrm{TM}}$ has a tensile strength of $230 \mathrm{MPa}^{17}$ We plan to switch to Upilex ${ }^{\mathrm{TM}}$ which has a tensile strength of 
$400 \mathrm{MPa} .{ }^{17,18}$ Therefore, if using our vapor deposition process, a conservative $50 \%$ of the literature strength value is obtained, we will have a reasonable safety margin for a NIF target.

\section{ACKNOWLEDGMENTS}

This work was performed under the auspices of the U. S. Department of Energy by the Lawrence Livermore National Laboratory under contract No. W-7405-ENG-48. We are grateful to Ed Lindsey and Derek Coker for collecting the SEM data.

\section{REFERENCES}

1. Dittrich, T. R.; Haan, S. W.; Pollaine, S.; Burnham, A. K. Fusion Technology 1997, 31,402 .

2. Sanchez, J. J.; Letts, S. A. Fusion Technology 1997, 31(4), 491.

3. Letts, S. A.; Myers, D. W.; Witt, L. A. J. Vac. Sci. Tech. 1981, 19, 739.

4. Collins, G.W.; Bittner, D.N.; Monsler, E.; Letts, S.; E.R. Mapoles; Bernat, T.P. J. Vac. Sci. Technol. A 1996, 14, 2897.

5. $\quad$ Mapoles, E. R. ; Sater, J.; Pipes, J.; Monsler, E., Phyical Rev. E 1997, 55, 3473.

6. Hoffer, J. K.; Sanchez, J. J.; Mapoles, E. R.; Sheliak, J. D.Fusion Tech. 1996, 30, 529;

Martin, A. J.; Simms, R. J.; Jacobs, R. B.J. Vac. Sci. Technol. A 1988, 6, 1885;

Hoffer, J. K.; Foreman, L. R.Phys. Rev. Lett. 1988, 60, 1310.

7. Marinak, M. M.; Haan, S. W.; Dittrich, T. R.; Tipton, R. E.; Zimmerman, G. E. Physics of Plasmas 1998, 5 (4), 1125.

8. Scroog, C. E. J. Polym. Sci.: Macrom. Rev. 1976, 11, 161.

9. Mittal, K. L.; Ghosh, M. K. Polyimides: Fundamentals and Applications; Marcel Dekker: New York, 1996.

10. Wilson, D.; Stenzenberger, H. D.; Hergenrother, P. M. Polyimides; Chapman and Hall: New York, 1990. 
11. Volksen, W. In High Performance Polymers, Adv. in Polym. Sci. series vol. 117, Hergenrother, P. M. Ed., Springer-Verlag: New York, 1994, p. 111.

12. Odian, G. Principles of Polymerization, 2nd Ed.; John Wiley \& Sons: New York, 1981, p. $82-88$.

13. Van Krevelen, D. W. Properties of Polymers, 3rd Ed.; Elsevier: New York, 1990, p. 412.

14. Young, R. J. In Comprehensive Polymer Science, Vol. 2, Booth, C.; Price, C. Eds.; Pergamon: New York, 1989, p. 51.

15. Wallach, M. L. J. Polym. Sci.:Part A-2 1968, 6, 953.

16. Volksen, W.; Cotts, P.; Yoon, D. Y. J. Polym. Sci.: Part B: Polym. Phys. 1987, 25, 2487.

17. Scroog, C. E. In ref. 10, p. 255.

18. Tensile strength data has been verified on site using ASTM D882.

19. Salem, J. R.; Sequeda, F. O.; Duran, J.; Lee, W. Y.; Yang, R. M. J. Vac. Sci. Tec. A 1986, 4, 369.

20. Strunskus, T.; Grunze, M. In ref. 9, p. 187.

21. Iijima, M.; Takahashi, Y. Macromol. 1989, 22, 2944.

22. Jou, J. H.; Cheng, C. L.; Jou, E. C. Y.; Yang, A. C. M. J. Polym. Sci.: Part B: Polym. Phys. 1996, 34, 2239.

23. Dimitrakopoulos, C. D.; Machlin, E. S.; Kowalczyk, S. P. Macromol. 1996, 29, 5818.

24. Malba, V.; Liberman, V.; Bernhardt, A. F. J. Vac. Sci. Tech. 1997, 15, 844.

25. Alfonso, E. L.; Chen, S. H.; Gram, R. Q.; Harding, D. R. LLE Review 1997, 71, 113; see also Alfonso, E. L.; Chen, S. H.; Gram, R. Q.; Harding, D. R. Fusion Tech., 1999, this issue.

26. Letts, S. A.; Fearen, E. M.; Allison, L. M.; Cook, R. J. Vac. Sci. Technol. A 1996, 14, 1015; Letts, S. A.; Fearon, E. M.; Buckley, S. R.; Saculla, M. D.; Allison, L. M.; Cook, R. Fusion Tech. 1995, 28, 1797. 
27. Numata, S.; Takayoshi, I.; Fujisaki, K.; Miwa, T.; Kinjo, N. U.S. Patent \#4,759,958 (1988).

28. Takekoshi, T. In ref. 9, p. 12-18.

29. Silverstein, R. M.; Bassler, G. C.; Morrill, T. C. Spectroscopic Identification of Organic Compounds, 4th Ed.; John Wiley \& Sons: New York, 1981.

30. D'Alelio, G. F. D., U.S. Patent \#3,979,416 (1976).

31. Lu, C.; Czanderna, A. W. Applications of Piezoelectric Quartz Crystal Microbalances; Elsevier Science Publishing: New York, 1984.

32. XTC/2 Deposition Monitor Manual; Leybold Inficon Inc.: East Syracuse, NY, 1997.

33. Dushman, S. Scientific Foundations of Vacuum Technique, 2ndEd.; John Wiley \& Sons: New York, 1962, p. 17-22.

34. Berman, A. Vacuum engineering calculations, formulas, and solved exercises; Academic Press: San Diego, 1992, p. 42.

35. Daniels, F.; Alberty, R. A. Physical Chemistry, 4th Ed.; John Wiley \& Sons: New York, 1975 , p. 98.

36. Pethe, R. G.; Carlin, C. M.; Patterson, H. H.; Unertl, W. N. J. Mater. Res. 1993, 8, 3218.

37. Hutchings, C. W.; Grunze, M. Rev. Sci. Instr. 1995, 66, 3943.

38. Detailed theoretical discussion maybe found in: 1) Ramsey, N. F. Molecular Beams;

Oxford University Press: London, 1956, p. 11. 2) Kennard, E. H. Kinetic Theory of Gases; McGraw-Hill Book Company:New York, 1938.

39. Sauerbrey, G. Z. Zeit. Phys. 1959, 155, 206; see also ref. 30.

40. St. Clair, T. L. In ref. 10 , p. 59. 